\title{
Comparative Evaluation of Seedling Hypocotyl Elongation and Mature Plant Assays for Determining Ethylene Sensitivity in Bedding Plants
}

\author{
Nichole F. Edelman, Bethany A. Kaufman, and Michelle L. Jones ${ }^{1}$ \\ Department of Horticulture and Crop Science, The Ohio State University, \\ Ohio Agricultural Research and Development Center, 1680 Madison \\ Avenue, Wooster, OH 44691
}

Additional index words. abscission, 1-aminocyclopropane-1-carboxylic acid (ACC), epinasty, flower senescence, leaf chlorosis, seedling triple response

\begin{abstract}
Ethylene gas can cause extensive damage to bedding plants during production, shipping, and retailing. Seedlings exposed to ethylene exhibit the triple response, which includes an exaggerated apical hook, thickened hypocotyl, and reduced hypocotyl elongation. Our objective was to determine if the hypocotyl elongation component of the seedling triple response could be used to predict the sensitivity of mature plants at the marketable stage. Eighteen common bedding plants were evaluated. For the seedling hypocotyl elongation screen, seeds were germinated and grown in the dark on filter paper saturated with various concentrations of 1-aminocyclopropane-1-carboxylic acid (ACC; the immediate precursor to ethylene). The relative hypocotyl length at each ACC concentration was compared with untreated control $(0 \mu \mathrm{M})$ seedlings. Mature plants, with at least four open flowers, were treated with ethylene $\left(0,0.01,0.1,1\right.$, or $\left.10 \mu \mathrm{L} \cdot \mathrm{L}^{-1}\right)$ in the dark for 24 hours. Phenotypic responses to ethylene, including flower abscission, flower senescence, leaf abscission, leaf chlorosis, and epinasty, were rated on a scale of 0 to 5. Five species exhibited very little reduction in hypocotyl elongation when grown on ACC (low sensitivity). The remaining species were classified as medium or high ethylene sensitivity at the seedling stage. The most common symptoms of ethylene damage observed in mature plants were leaf epinasty, flower abscission, and flower senescence. The severity of these responses was used to identify plants with high, medium, or low sensitivity to ethylene. For six of the bedding plant species that were equally responsive at both developmental stages, the seedling hypocotyl elongation screen would provide a reliable means of predicting the ethylene sensitivity of mature plants.
\end{abstract}

Ethylene $\left(\mathrm{C}_{2} \mathrm{H}_{4}\right)$ is a gaseous plant hormone that is produced by plants during normal development and in response to biotic and abiotic stresses (Abeles et al., 1992). Ethylene is involved in seed germination, stem elongation, abscission, epinasty, senescence, and fruit ripening. Plant responses to ethylene depend on the concentration and exposure time (i.e., dosage) as well as the

Received for publication 20 Aug. 2013. Accepted for publication 4 Feb. 2014.

Salaries and research support were provided in part by State and Federal funds appropriated to the Ohio Agricultural Research and Development Center, The Ohio State University. Journal Article Number HCS 13-12. Research was funded by the D.C. Kiplinger Endowment and the American Floral Endowment Gus Poesch Fund. Seeds were provided by the Ball Horticultural Company.

We thank Dr. David Francis and Shaun Broderick for assistance with the statistical analyses and Laura Chapin and Eileen Ramsay for assistance with the research and the manuscript. We also acknowledge the financial support from the OARDC research internship program for Bethany Kaufman.

${ }^{1}$ To whom reprint requests should be addressed; e-mail jones.1968@osu.edu. plant's sensitivity to ethylene. Ethylene sensitivity varies by species, ranging from nonresponsive to highly sensitive. Ethylene sensitivity can also vary depending on developmental age or organ type (i.e., flowers, leaves, or roots) (Abeles et al., 1992; Woltering, 1987; Woodson and Lawton, 1988).

Seedlings that are exposed to ethylene exhibit the triple response, which includes an exaggerated apical hook, hypocotyl thickening, and reduced hypocotyl elongation (Knight et al., 1910). This response has been used in genetic screens to identify ethylene response mutants, including the etr1-1 mutation, which confers ethylene insensitivity in Arabidopsis thaliana seedlings (Chang et al., 1993). The seedling triple response screen has successfully identified many genes involved in both ethylene biosynthesis and perception (Guzman and Ecker, 1990). This screen involves growing seedlings in the dark in the presence of ACC, the immediate precursor to ethylene. In the presence of oxygen, ACC is converted to ethylene by constitutive levels of ACC oxidase in the seedlings (Yang and Adams, 1979). These evaluations must be conducted on dark-grown seedlings, because ethylene promotes hypocotyl elongation in the light (Alonso et al., 1999;
Ecker, 1995; Smalle et al., 1997; Zhong et al., 2012).

The effects of ethylene on hypocotyl elongation are concentration-dependent, and hypocotyl length decreases (in the dark) with increasing ethylene or ACC concentration until the response is saturated (Bleecker et al., 1988; Goeschl and Kays, 1975; Lanahan et al., 1994). Clark et al. (2001) used the hypocotyl elongation response (a component of the seedling triple response) to evaluate the ethylene sensitivity of dark-grown geranium (Pelargonium $\times$ hortorum) seedlings. Seedlings from all six cultivars showed a reduction in hypocotyl length that correlated with ACC concentration and indicated that they were sensitive to ethylene. The average hypocotyl lengths at various ACC concentrations were used to determine differences in ethylene sensitivity among the cultivars. Petal abscission rates after exposure to various concentrations of ethylene were also used to determine the ethylene sensitivity of mature geranium plants. In this experiment, ethylene sensitivity as determined by the hypocotyl elongation screen correlated with sensitivity as determined by petal abscission. These results suggest that a seedling hypocotyl elongation screen could be used to predict ethylene sensitivity in mature plants, but additional experiments need to be conducted to determine if the seedling hypocotyl response accurately and consistently predicts mature plant sensitivity to ethylene in other species.

Exposure to ethylene during greenhouse production, shipping, and retailing can reduce the shelf life and garden performance of ornamental plants. Ethylene-induced petal senescence, flower abscission, epinasty, leaf chlorosis, and leaf abscission make crops unmarketable and increase postproduction shrink (Jones and Edelman, 2013; Jones and Ling, 2012). Researchers have investigated the ethylene responsiveness of numerous ornamentals, and these studies have identified plants or flowers that are sensitive or relatively insensitive to ethylene. It is difficult to use these reports to classify the ethylene sensitivity of these plants because the assessments are all based on different ethylene concentrations, durations of treatment, and methods for evaluating responses (Alexander and Grierson, 2002; Barry et al., 2001; Dole et al., 2009; Goto et al., 1999; Ichimura and Suto, 1998; Serek et al., 1995). Woltering (1987) published a standardized protocol for evaluating ethylene sensitivity that was based on treating mature plants from 52 ornamental species with four concentrations of ethylene for two different exposure times. The severity of the different ethylene responses was used to classify the plants into a sensitivity class from zero to eight.

It is important for floriculture producers, plant breeders, extension professionals, and researchers to know which plants are sensitive to ethylene and to be able to identify differences in ethylene sensitivity between cultivars. This information can be used by producers to identify the best cultivars for long-distance transport and to determine 
which crops would benefit from treatment with ethylene inhibitors like 1-methylcyclopropene (1-MCP). It would therefore be extremely valuable to develop a rapid and simple screen for evaluating ethylene sensitivity at the seedling stage rather than treating large mature plants. Breeders could use this high-throughput screen to determine the ethylene sensitivity classification for new PIs and to identify less sensitive breeding lines.

The objective of this research was to determine if the seedling hypocotyl elongation screen could be used to predict the sensitivity of mature plants at the marketable stage. To determine the utility of this screen, we developed a protocol for evaluating ethylene sensitivity in seedlings germinated and grown in the dark on filter paper saturated with various ACC concentrations. A comparative study was conducted in mature plants using a modified version of the screening protocols described by Woltering (1987). These initial studies focused on evaluating ethylene sensitivity in popular bedding plant species.

\section{Materials and Methods}

Seedling hypocotyl elongation screen. The effect of ACC on seedling hypocotyl length was evaluated in 18 bedding plant species (Table 1). ACC stock solutions were filter-sterilized (Nalgene Filtration Products, Rochester, NY), and serial dilutions were brought to volume with autoclaved $\mathrm{ddH}_{2} \mathrm{O}$. Seeds were sown in petri dishes containing sterile filter paper saturated with $1000 \mu \mathrm{L}$ of $0,0.01,0.05,0.1,0.5,1,5,10,50$, or $100 \mu \mathrm{M}$ ACC. Concentrations were chosen based on previous seedling screens using ACC (Smalle et al., 1997). Initial studies comparing filter paper saturated with ACC vs. Murashige and Skoog (MS) media containing ACC indicated that hypocotyl elongation responses were comparable (Supplemental Fig. 1). Plates were sealed with parafilm and placed in the dark at $23{ }^{\circ} \mathrm{C}$ for 7 to $14 \mathrm{~d}$. There were 10 treatments (concentrations) per cultivar, four replicates (plates) sown per concentration of ACC, and six seeds sown per replicate. The experiment was performed twice and each trial represented one block. Seedlings were

Table 1. Ethylene classifications from seedling hypocotyl elongation and mature plant screens.

\begin{tabular}{|c|c|c|c|}
\hline Plants & $\begin{array}{l}\text { Seedling } \\
\text { sensitivity }\end{array}$ & $\begin{array}{l}\text { Mature plant } \\
\text { sensitivity }^{\mathrm{y}}\end{array}$ & $\begin{array}{l}\text { Mature plant } \\
\text { symptoms }^{\mathrm{x}}\end{array}$ \\
\hline $\begin{array}{l}\text { Ageratum houstonianum } \\
\text { 'High Tide Blue' }\end{array}$ & High & High & Leaf epinasty \\
\hline $\begin{array}{l}\text { Angelonia angustifolia } \\
\text { 'Serena Lavender Pink' }\end{array}$ & Low & Low & $\begin{array}{l}\text { Flower abscission, flower } \\
\text { senescence }\end{array}$ \\
\hline $\begin{array}{l}\text { Antirrhinum majus (snapdragon) } \\
\text { 'Bedding Rocket Lemon' }\end{array}$ & High & Medium & Flower abscission \\
\hline $\begin{array}{l}\text { Dahlia } \times \text { hybrida } \\
\text { 'Figaro White' }\end{array}$ & Low & Medium & $\begin{array}{l}\text { Flower abscission, flower } \\
\text { senescence, leaf epinasty }\end{array}$ \\
\hline $\begin{array}{l}\text { Gomphrena globosa } \\
\text { 'Fireworks' }\end{array}$ & Medium & No response & None \\
\hline $\begin{array}{l}\text { Lobelia erinus } \\
\text { 'Regatta Rose' }\end{array}$ & Low & High & Flower senescence \\
\hline $\begin{array}{l}\text { Lobularia maritima (alyssum) } \\
\text { 'Snow Crystals' }\end{array}$ & High & Medium & $\begin{array}{l}\text { Flower abscission, leaf } \\
\text { chlorosis }\end{array}$ \\
\hline $\begin{array}{l}\text { Nemesia fruticans } \\
\text { 'Poetry Blue' }\end{array}$ & High & High & $\begin{array}{l}\text { Flower abscission, flower } \\
\text { senescence }\end{array}$ \\
\hline $\begin{array}{l}\text { Petunia } \times \text { hybrida } \\
\text { 'Carpet White' }\end{array}$ & Medium & High & Flower senescence \\
\hline $\begin{array}{l}\text { Phlox drummondii } \\
\text { 'Palona Light Salmon' }\end{array}$ & High & Medium & $\begin{array}{l}\text { Flower abscission, flower } \\
\text { senescence }\end{array}$ \\
\hline $\begin{array}{l}\text { Portulaca grandiflora } \\
\text { 'Margarita Scarlet' }\end{array}$ & Medium & High & $\begin{array}{l}\text { Flower senescence, leaf } \\
\text { abscission }\end{array}$ \\
\hline $\begin{array}{l}\text { Salvia splendens } \\
\text { 'Red Hot Sally' }\end{array}$ & Low & High & $\begin{array}{l}\text { Flower abscission, leaf } \\
\text { epinasty }\end{array}$ \\
\hline $\begin{array}{l}\text { Solanum lycopersicum (tomato) } \\
\text { 'Tumbler' }\end{array}$ & High & High & $\begin{array}{l}\text { Flower abscission, leaf } \\
\text { epinasty }\end{array}$ \\
\hline $\begin{array}{l}\text { Tagetes patula (french marigold) } \\
\text { 'Durango Bee' }\end{array}$ & Medium & Medium & Leaf epinasty \\
\hline $\begin{array}{l}\text { Torenia fournieri } \\
\text { 'Clown Blue' }\end{array}$ & Medium & High & Flower abscission \\
\hline $\begin{array}{l}\text { Viola cornuta } \\
\text { 'Sorbet XP Orange' }\end{array}$ & High & Low & Flower senescence \\
\hline $\begin{array}{l}\text { Viola } \times \text { witrockiana (pansy) } \\
\text { 'Matrix Lemon' }\end{array}$ & High & Low & Flower senescence \\
\hline $\begin{array}{l}\text { Zinnia marylandica } \\
\text { 'Double Zahara Fire' }\end{array}$ & No response & Low & Flower senescence \\
\hline
\end{tabular}

zSeedling sensitivity was based on the relative hypocotyl length at $100 \mu \mathrm{M}$ 1-aminocyclopropane-1carboxylic acid (ACC) compared with controls $(0 \mu \mathrm{M}$ ACC). The classifications included low ( $80 \%$ to $100 \%)$, medium $(50 \%$ to $79 \%$ ), and high (below $50 \%$ ).

${ }^{\mathrm{y}}$ Mature plant sensitivity was determined by sensitivity ratings ( 0 to 5$)$ taken at $0 \mathrm{~d}$ in response to treatment with $10 \mu \mathrm{L} \cdot \mathrm{L}^{-1}$ exogenous ethylene. The classification low $(0 \%$ to $20 \%$; rating 5 and 4$)$, medium $(21 \%$ to $40 \%$; rating 3 ), and high ( $41 \%$ to $100 \%$; rating 2,1 , and 0$)$ was assigned based on the lowest rating (i.e., the most severe symptom) received for an observed symptom.

${ }^{\mathrm{x}}$ Symptoms observed when horticulturally mature plants were treated with $10 \mu \mathrm{L} \cdot \mathrm{L}^{-1}$ ethylene for $24 \mathrm{~h}$. scanned using WinRhizo (Regent Instruments Inc., Canada) imaging software and hypocotyl lengths were measured using ImageJ Software (Abramoff et al., 2004). The hypocotyl length, as a percentage of the control, was calculated for each seedling and averaged for each treatment (length of seedling/average length of control $\times 100$ ). This is referred to as the relative hypocotyl length. Seedling ethylene sensitivity was defined as high when relative hypocotyl lengths were below $50 \%$; medium at $50 \%$ to $79 \%$; and low at $80 \%$ to $100 \%$ based on cutoffs determined by statistical analysis at $100 \mu \mathrm{M}$ ACC. These sensitivity ratings are included in Table 1 .

The seedling hypocotyl elongation response was compared in lobelia 'Regatta Rose' and tomato 'Tumbler' seedlings grown on ACC or treated with ethylene gas. Control seedlings were sown on filter paper saturated with $\mathrm{ddH}_{2} \mathrm{O}$. ACC-treated seedlings were sown on filter paper saturated with $100 \mu \mathrm{M}$ ACC. Ethylene-treated seedlings were sown on filter paper saturated with $\mathrm{ddH}_{2} \mathrm{O}$ and grown in a 24-L Plexiglas chamber into which pure ethylene gas was injected to a final concentration of $10 \mu \mathrm{L} \cdot \mathrm{L}^{-1}$. Control and ACC treated seedlings were grown in a similar chamber with no added ethylene. All chambers were aired out daily for $30 \mathrm{~min}$ and ethylene was added to the desired concentration $\left(0\right.$ or $\left.10 \mu \mathrm{L} \cdot \mathrm{L}^{-1}\right)$. Ethylene concentrations in the chambers were monitored with a gas chromatograph and adjusted as needed (Varian 3800; Agilent, Foster City, CA). Chambers were held in the dark at $23{ }^{\circ} \mathrm{C}$ for the duration of the experiment. After $7 \mathrm{~d}$ (tomato) or $14 \mathrm{~d}$ (lobelia), seedling hypocotyl elongation was determined as described previously.

Plant culture for mature plant screen. Seeds of all 18 species (Table 1) were sown in 128-count plug trays using Promix (Premier Tech Horticulture Ltd., Canada) and grown under constant, full-spectrum fluorescent lights. Plants were irrigated by hand as needed and fertilized with $100 \mathrm{mg} \cdot \mathrm{L}^{-1}$ nitrogen $(\mathrm{N})$ from $15 \mathrm{~N}-2.2 \mathrm{P}-12.5 \mathrm{~K}$ Peter's Excel Cal-Mag (Everis International BV ICL Fertilizers Co., Dublin, OH). Two- to 3-weekold seedlings were moved to the greenhouse where they acclimated for 2 weeks before being transplanted into 4.5 -in $(11.4 \mathrm{~cm})$ diameter plastic pots. Plants were irrigated by hand as needed, alternating between $150 \mathrm{mg} \cdot \mathrm{L}^{-1} \mathrm{~N}$ from $15 \mathrm{~N}-2.2 \mathrm{P}-12.5 \mathrm{~K}$ Peter's Excel Cal-Mag and $250 \mathrm{mg} \cdot \mathrm{L}^{-1} \mathrm{~N}$ from $20 \mathrm{~N}-$ 4.37P-16.6K Peter's Professional (Everis International BV ICL Fertilizers Co.). Average greenhouse temperatures were $26 / 21 \pm 4 / 2{ }^{\circ} \mathrm{C}$ day/night with relative humidity of $45.6 \% \pm$ $18.3 \%$. Plants were grown under natural irradiance from Apr. 2011 to June 2012.

Mature plant ethylene treatments. Experiments were conducted from Sept. 2011 to June 2012. In this experiment, our mature plants were market-ready bedding plants (Watada et al., 1984) that had four or more open flowers. There were five ethylene treatments per cultivar and four replicates per concentration with each plant acting as 
a replicate. The experiment was performed twice and each trial represented one block. Plants were placed into 55-gal (208 L) metal chambers that were sealed with Plexiglas lids and held in a room at $23{ }^{\circ} \mathrm{C}$. Ethylene gas was injected into the chambers to obtain the final concentrations of $0,0.01,0.1,1.0$ or $10 \mu \mathrm{L} \cdot \mathrm{L}^{-1}$, and the lids were covered with cloth to keep plants in the dark. The ethylene concentrations inside the chambers were regularly tested with a gas chromatograph and adjusted as needed (Varian 3800; Agilent). Mature plants were removed from the chambers after a 24-h treatment. Visual observations and photographs were taken at 0 (immediately after ethylene exposure), 1, 2, 5, and $7 \mathrm{~d}$. Plants were evaluated for symptoms of flower abscission (drop), flower senescence (wilt), leaf abscission, leaf chlorosis (yellowing), and leaf epinasty (downward curvature). Flower evaluations did not distinguish between open flowers and buds, and both were included in senescence and abscission ratings. The severity of the ethylene damage on each plant was evaluated using a 0 to 5 rating scale. Ratings were based on the percentage of the plant exhibiting symptoms with $5=0 \%$ (no damage), $4=1 \%$ to $20 \%, 3=21 \%$ to $40 \%, 2=41 \%$ to $60 \%, 1=61 \%$ to $80 \%$, and $0=81 \%$ to $100 \%$. For vegetative symptoms, a rating of 4 indicated that $1 \%$ to $20 \%$ of the leaves showed epinasty or that $1 \%$ to $20 \%$ of the leaves were yellowing or had abscised. For floral symptoms, a rating of 4 meant that $1 \%$ to $20 \%$ of the flowers on that plant had abscised or wilted (senesced). An overall sensitivity rating for the plant was then assigned based on the ethylene damage symptom that received the highest rating after treatment with $10 \mu \mathrm{L} \cdot \mathrm{L}^{-1}$ ethylene at $0 \mathrm{~d}$ (Table 1 ).

Statistical analysis. The experiments were conducted using a complete block design and data were analyzed in SAS (Version 9.3; SAS Institute, Cary, NC). For the seedling screen, percentages obtained from hypocotyl measurements were analyzed using PROC GLIMMIX (generalized linear mixed models). All means were adjusted for errors in model and presented as least squares means. Proc univariate was used to determine that visual observation data for mature plants were
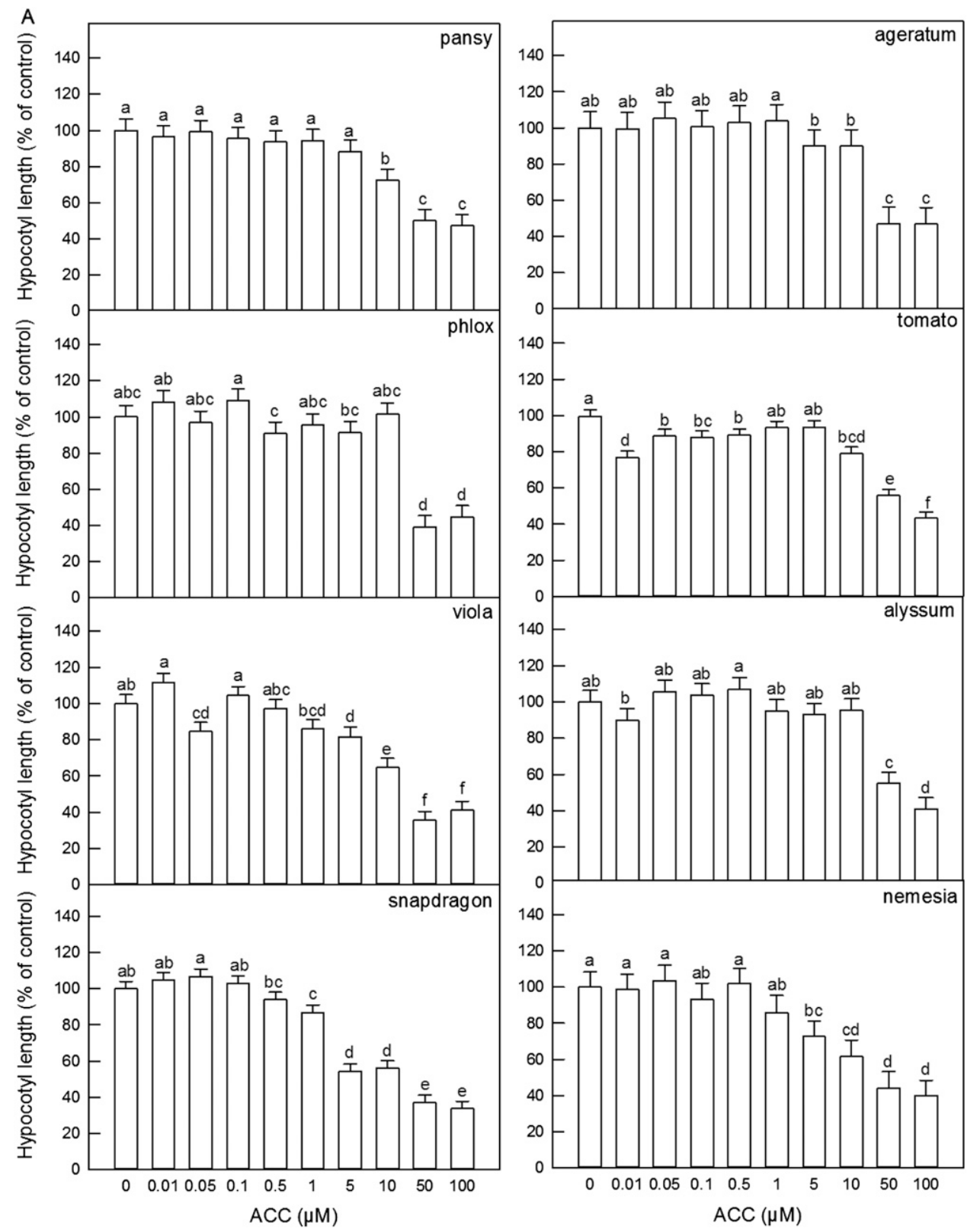

Fig. 1. Evaluation of the hypocotyl elongation screen in 18 bedding plant species. Seeds were sown on filter paper saturated with 1-aminocyclopropane-1carboxylic acid (ACC) at $0,0.01,0.05,0.1,0.5,1,5,10,50$, or $100 \mu \mathrm{M}$. Seedling hypocotyl length was measured at 7 to $14 \mathrm{~d}$ after germination. Bars represent the relative hypocotyl length as a percent of the control $(0 \mu \mathrm{M} \mathrm{ACC})$ for each concentration. Error bars represent the SE, and letters above the error bars represent significance between treatments based on separation presented as the least squares means using $\alpha=0.05$ for significance. Plant species were categorized as having high (A), medium (B), or low (C) ethylene sensitivity. 

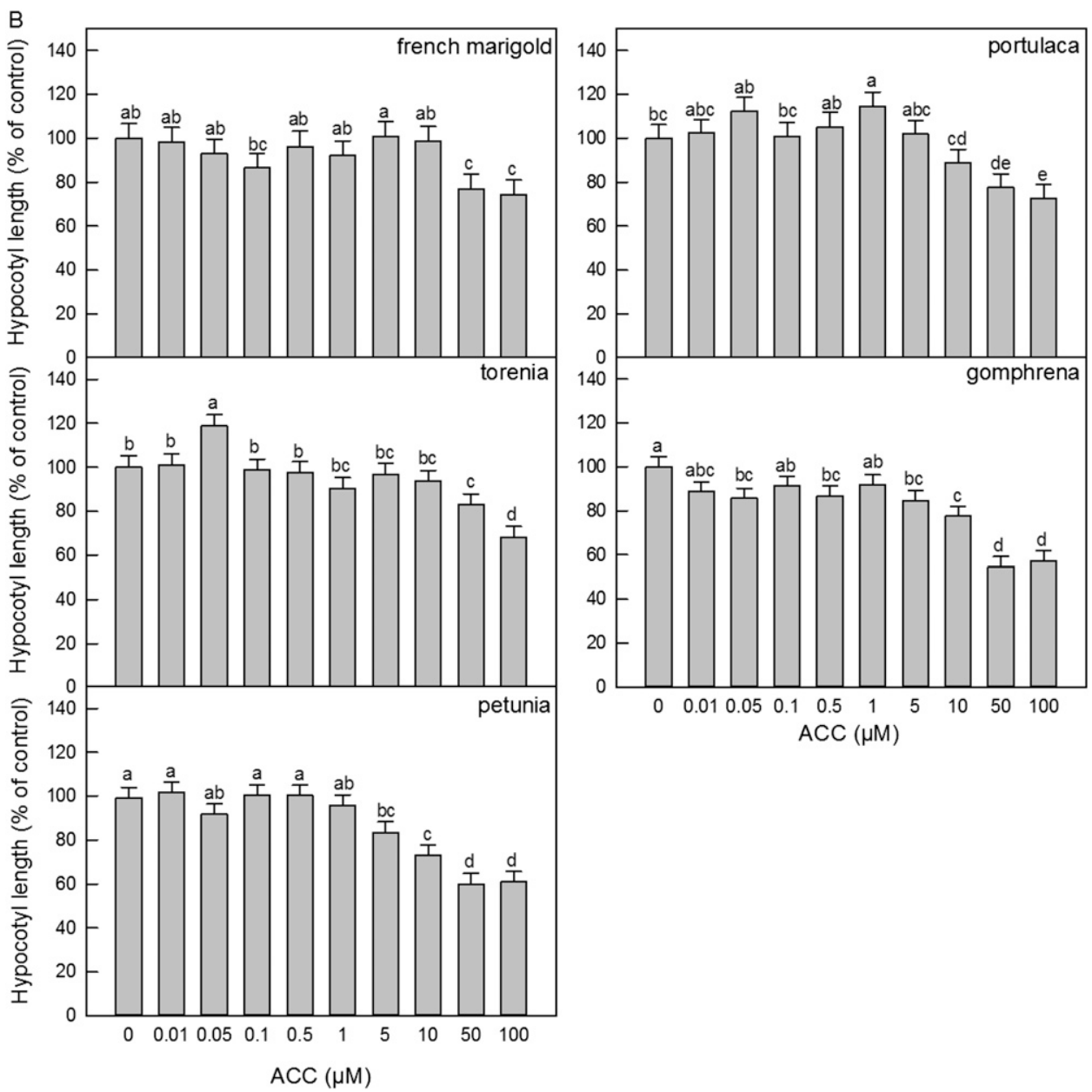

Fig. 1. Continued.

normally distributed (i.e., that no data transformation was necessary). Data proved to be normally distributed and therefore were analyzed using PROC GLM (generalized linear model). All means were adjusted for errors in model and presented as least squares means. All statistical tests used $\alpha=$ 0.05 for significance.

\section{Results}

Ethylene sensitivity of seedlings. Thirteen species exhibited a decrease in hypocotyl length with increasing ACC concentrations (high and medium sensitivity), whereas five species showed little change in hypocotyl length when compared with seedlings germinated with no ACC (low sensitivity) (Fig. 1). The greatest decreases in hypocotyl length were observed among pansy, ageratum, phlox, tomato, viola, alyssum, snapdragon, and nemesia (Fig. 1A). Snapdragon seedlings responded to concentrations as low as $5 \mu \mathrm{M}$, whereas pansy, viola, and nemesia had an ethyleneinduced decrease in hypocotyl length at $10 \mu \mathrm{M}$ ACC. For ageratum, phlox, tomato, and alyssum, initial reductions in hypocotyl length were observed at $50 \mu \mathrm{M}$ ACC. The relative hypocotyl length at $100 \mu \mathrm{M}$ ACC varied from $47.2 \%$ (pansy) to $33.7 \%$ (snapdragon) as compared with controls.
French marigold, portulaca, torenia, petunia, and gomphrena had a smaller reduction in hypocotyl length. The relative hypocotyl length at $100 \mu \mathrm{M}$ ACC varied from $74.2 \%$ (french marigold) to $57.2 \%$ (gomphrena) (Fig. 1B). French marigold, petunia, and gomphrena had a decrease in hypocotyl length at $50 \mu \mathrm{M}$ ACC, whereas torenia and portulaca did not show a response until $100 \mu \mathrm{M}$. No effects of ACC on hypotocyl length were observed for zinnia, dahlia, lobelia, salvia, or angelonia (Fig. 1C).

For the seedling hypocotyl elongation screen, we used 10 concentrations of ACC to determine the lowest concentration at which a reduction in hypocotyl length could be observed. Although differences in ethylene responsiveness among the species were noted at various ACC concentrations, they were most significant at the $100 \mu \mathrm{M}$ ACC treatment (Fig. 2). The relative hypocotyl length at $100 \mu \mathrm{M}$ was therefore used to classify seedlings as having high, medium, or low sensitivity to ethylene (Table 1).

Ethylene sensitivity of mature plants. Plants were rated on a scale of 0 to 5 for flower abscission (Fig. 3A), flower senescence (Fig. 3B), leaf epinasty, leaf abscission, and leaf chlorosis (Fig. 4) after treatment with ethylene. Immediately after exposure to exogenous ethylene for $24 \mathrm{~h}$
(0 d), flower abscission was observed in $44 \%$ of the species that were evaluated (Figs. $3 \mathrm{~A}$ and 5 ). Open flowers were generally more sensitive to ethylene than buds. Abscission rates were highest among open flowers, although all of the plants that abscised flowers also abscised a few buds. The greatest response was seen in salvia and torenia with $81 \%$ to $100 \%$ flower abscission (rating of 0 ) after treatment with $10 \mu \mathrm{L} \cdot \mathrm{L}^{-1}$ ethylene. At this same ethylene concentration, nemesia and tomato showed $61 \%$ to $80 \%$ flower abscission (rating of 1), whereas alyssum received an average rating of 2.6 , snapdragon 3.5 , and phlox and dahlia $3(\approx 21 \%$ to $40 \%$ flower abscission). In contrast, angelonia showed much lower abscission (rating 4.5). Torenia abscised flowers at concentrations as low as $0.01 \mu \mathrm{L} \cdot \mathrm{L}^{-1}$, whereas flower loss was first observed in nemesia, phlox, salvia, and tomato treated with $0.1 \mu \mathrm{L} \cdot \mathrm{L}^{-1}$ ethylene. Alyssum, angelonia, dahlia, and snapdragon did not show significant flower abscission until concentrations of ethylene were $1 \mu \mathrm{L} \cdot \mathrm{L}^{-1}$. Plants were also rated at 1, 2 (Supplemental Figs. 2, 3, 4, and 5), 5, and $7 \mathrm{~d}$ (data not shown) after ethylene treatment to determine when the most extensive ethylene damage would be observed. Snapdragon continued to abscise flowers, decreasing from a rating of 3.5 at $0 \mathrm{~d}$ to 2 at $5 \mathrm{~d}$ (data not shown). The oldest fully open flowers abscised first at $0 \mathrm{~d}$ followed by the younger 


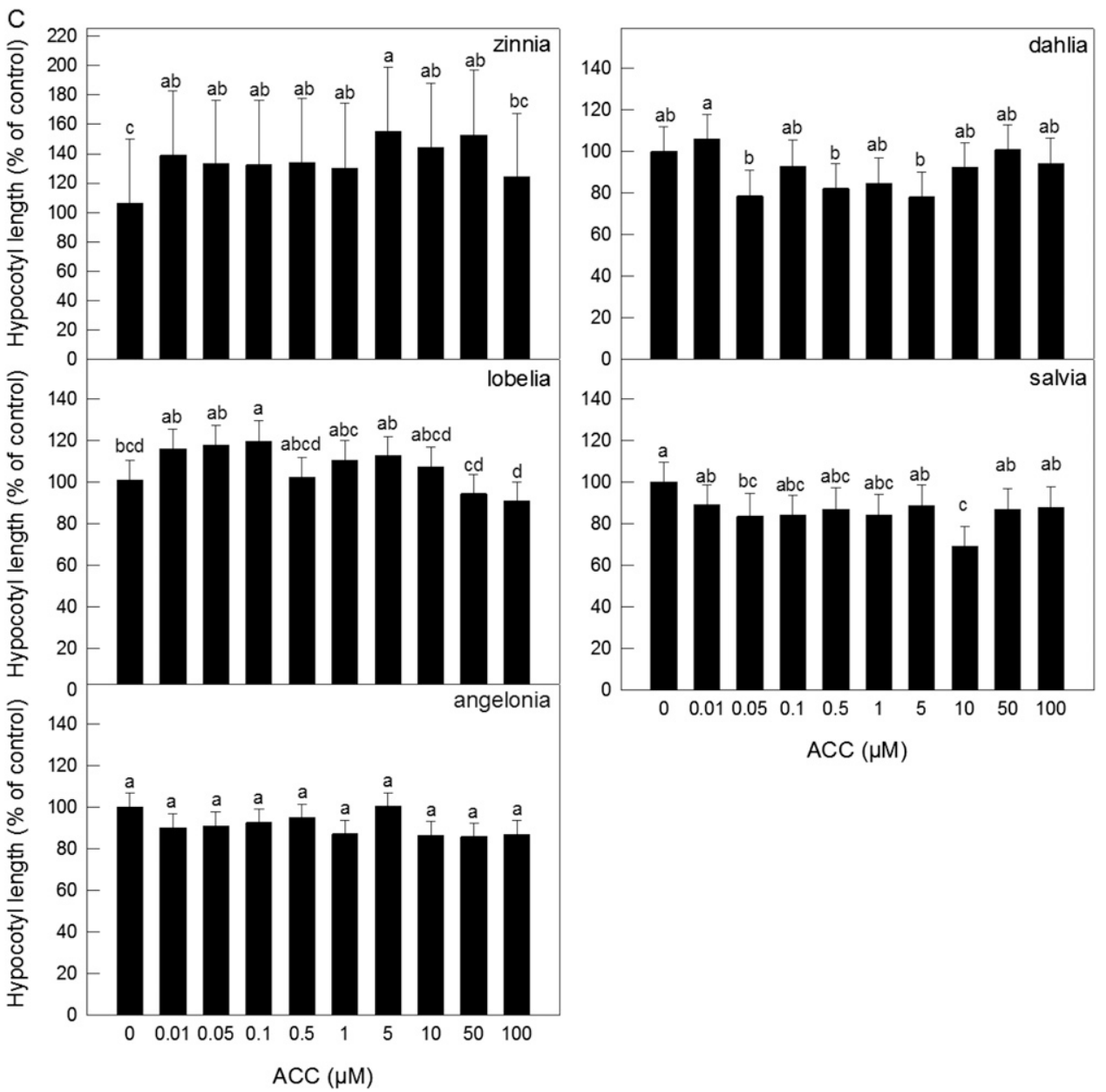

Fig. 1. Continued.

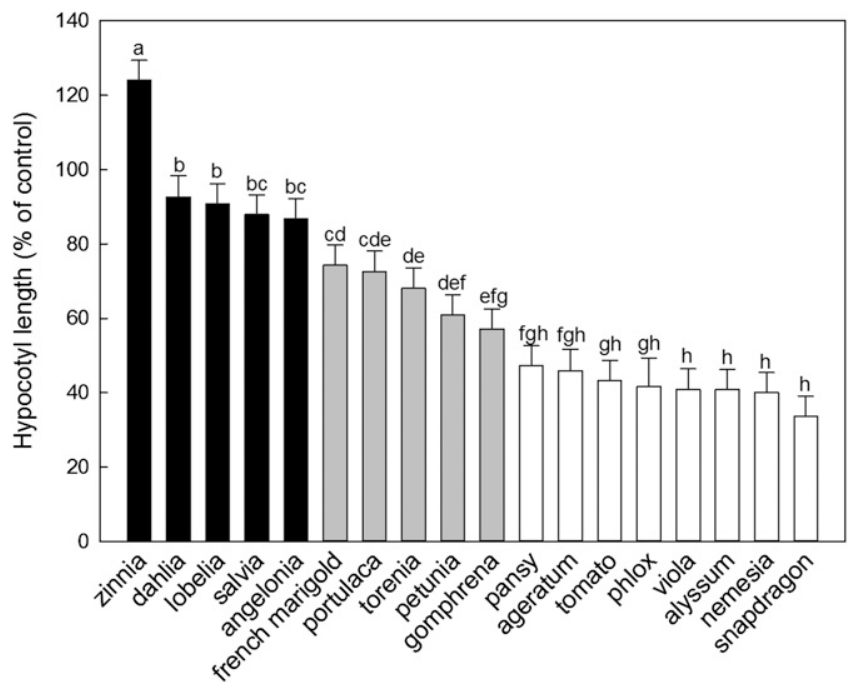

Fig. 2. Relative hypocotyl lengths of seedlings germinated on $100 \mu \mathrm{M}$ 1-aminocyclopropane-1-carboxylic acid (ACC). Bars represent the hypocotyl length at $100 \mu \mathrm{M}$ ACC as a percentage of the controls $(0 \mu \mathrm{M}$ $\mathrm{ACC}$ ). Error bars represent the SE and letters above the error bars represent significance between species based on the separation presented as the least squares means using $\alpha=0.05$ for significance. Species were categorized as having high (white bars), medium (gray bars), or low (black bars) ethylene sensitivity.

flowers at the top of the inflorescence on subsequent days. For all other species, no significant increase in flower abscission was observed on 1, 2 (Supplemental Figs. 2A and $4 \mathrm{~A}), 5$, or $7 \mathrm{~d}$ (data not shown)
Flower senescence was observed in 10 of the 18 species after exposure to ethylene (Figs. $3 \mathrm{~B}$ and 5). Immediately after the ethylene treatment $(0 \mathrm{~d})$, petunia had the most senescing flowers (rating of 0 at $10 \mu \mathrm{L} \cdot \mathrm{L}^{-1}$ ) and petal wilting was observed at concentrations as low as $0.01 \mu \mathrm{L} \cdot \mathrm{L}^{-1}$. Flower senescence was observed in dahlia, portulaca, and lobelia treated with $0.1 \mu \mathrm{L} \cdot \mathrm{L}^{-1}$ ethylene. Dahlia received a rating of 4 and both lobelia and portulaca received a rating of 2 at $10 \mu \mathrm{L} \cdot \mathrm{L}^{-1}$. Angelonia, nemesia, pansy, phlox, viola, and zinnia were given a rating of 4 after $24 \mathrm{~h}(0 \mathrm{~d})$ of treatment with $10 \mu \mathrm{L} \cdot \mathrm{L}^{-1}$ ethylene due to the presence of a few wilted flowers. Only open flowers senesced, and by Day 2, the buds that had not abscised were opening.

Vegetative symptoms of ethylene damage included leaf abscission, chlorosis, and epinasty (Figs. 4 and 5). Ageratum, dahlia, french marigold, tomato, and salvia exhibited leaf epinasty (downward curvature of the leaf petiole) at $0 \mathrm{~d}$ (Figs. 4 and 5F). The most severe epinastic response was observed in tomato ( 0 rating) and ageratum ( 1.5 rating) at $10 \mu \mathrm{L} \cdot \mathrm{L}^{-1}$. Tomato and ageratum responded to ethylene concentrations as low as $0.1 \mu \mathrm{L} \cdot \mathrm{L}^{-1}$. Epinasty was observed in french marigold at $1 \mu \mathrm{L} \cdot \mathrm{L}^{-1}$, and plants received a rating of 3 at $10 \mu \mathrm{L} \cdot \mathrm{L}^{-1}$. Dahlia responded with leaf epinasty after treatment with $10 \mu \mathrm{L} \cdot \mathrm{L}^{-1}$ ethylene (3.5 rating). Epinasty in french marigolds was only observed in the uppermost (youngest) leaves (top 30\%) and full recovery (back to a rating of 5) was observed within $24 \mathrm{~h}$ (by the 1-d observation; Supplemental 

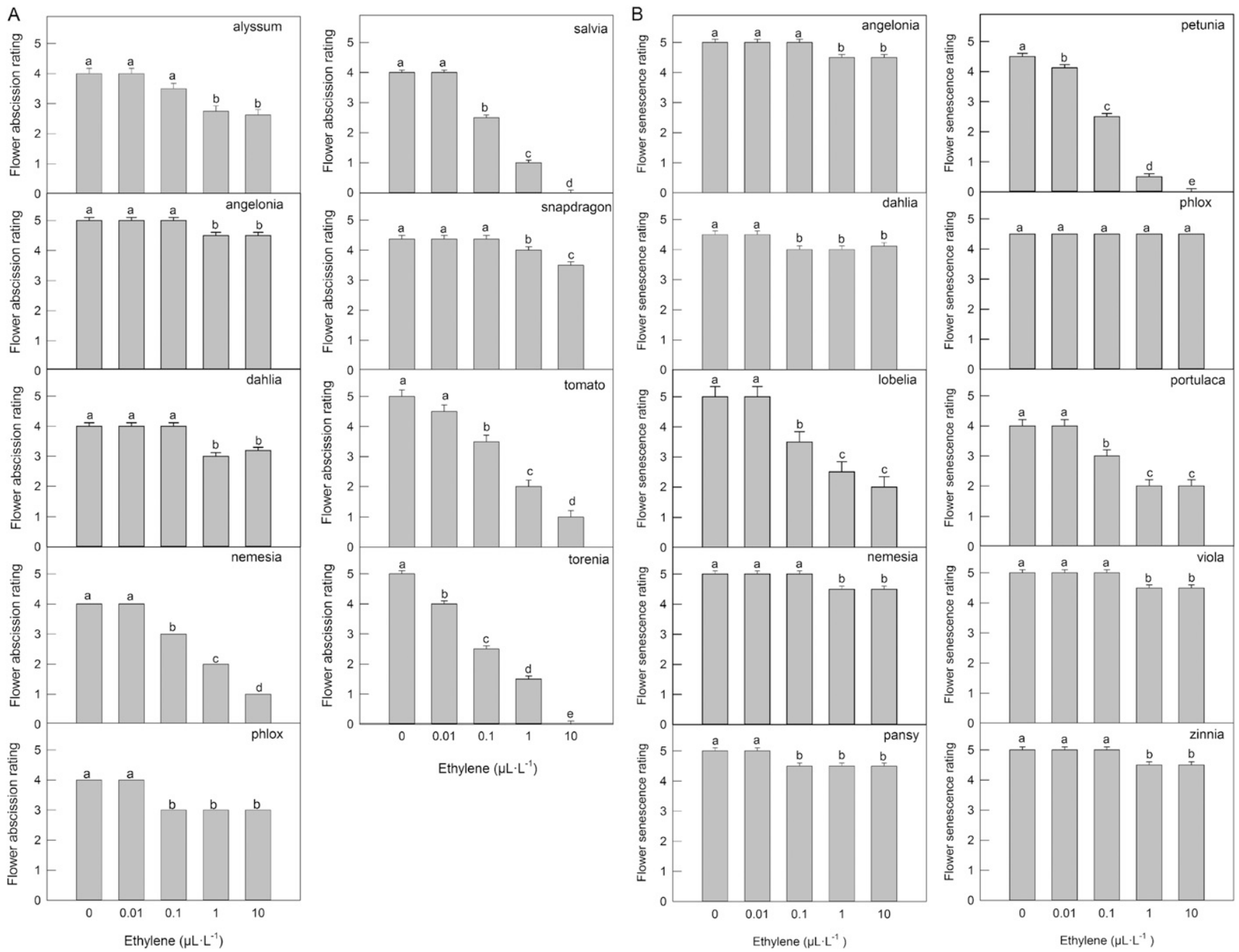

Fig. 3. Flower quality of mature plants immediately after treatment $(0 \mathrm{~d})$ with ethylene. Species exhibiting flower abscission $(\mathbf{A})$ and flower senescence (B) after treatment with $0,0.01,0.1,1$, or $10 \mu \mathrm{L} \cdot \mathrm{L}^{-1}$ ethylene for $24 \mathrm{~h}$. Ratings were assigned based on the percentage of flowers on the plant showing symptoms: $5=0 \%, 4=1 \%$ to $20 \%, 3=21 \%$ to $40 \%, 2=41 \%$ to $60 \%, 1=61 \%$ to $80 \%, 0=81 \%$ to $100 \%$. Bars represent the average visual rating, error bars represent the SE, and letters above the error bars show significance based on separation presented as the least squares means using $\alpha=0.05$ for significance.

Fig. 3). Dahlia and salvia were recovered at $1 \mathrm{~d}$ (Supplemental Fig. 3), and tomato and ageratum were recovered at $2 \mathrm{~d}$ (Supplemental Fig. 5).

The only species to exhibit leaf abscission was portulaca. Extensive leaf abscission was observed on $0 \mathrm{~d}$ when portulaca were treated with $10 \mu \mathrm{L} \cdot \mathrm{L}^{-1}$ ethylene (Figs. 4 and 5D). Plants lost approximately half of their leaves and received an average rating of 2.5. A response was observed at concentrations as low as $0.1 \mu \mathrm{L} \cdot \mathrm{L}^{-1}$. Portulaca continued to lose leaves at $1 \mathrm{~d}$, and the average rating decreased to 2.0 (Supplemental Fig. 3). The only species to exhibit leaf chlorosis was alyssum. The lower (oldest) leaves showed accelerated yellowing and senescence, and an average rating of 3.5 was assigned to plants treated with $10 \mu \mathrm{L} \cdot \mathrm{L}^{-1}$. We continued to observe symptoms and record ratings through $7 \mathrm{~d}$ to determine if there would be any delays in the visual appearance of leaf chlorosis after removal from the ethylene gas. We did not observe any changes in the extent of leaf chlorosis in alyssum, and no other species developed leaf chlorosis symptoms over time (Supplemental Figs. 3 and 5, data not shown).

The severity of symptoms varied among species (Table 1). Gomphrena was the only species that did not exhibit a response to the ethylene treatment. It was classified as no response instead of insensitive because it may respond to higher ethylene dosages (i.e., increased exposure time and/or increased ethylene concentrations). Ageratum, french marigold, lobelia, pansy, petunia, snapdragon, torenia, viola, and zinnia each exhibited only a single symptom (flower abscission, flower senescence, leaf abscission, leaf chlorosis, or leaf epinasty). In contrast, alyssum, angelonia, dahlia, nemesia, phlox, portulaca, salvia, and tomato exhibited multiple symptoms when treated with ethylene.

Classification of seedling and mature plant ethylene sensitivity. Seedlings and mature plants of the 18 bedding plant species were grouped into one of three ethylene sensitivity classifications (Table 1). Although most of the species had similar trends in ethylene responsiveness between the seedling stage and the mature stage, there were four exceptions. Lobelia and salvia were classified as low sensitivity at the seedling stage and high at the mature stage, whereas pansy and viola had low sensitivity at the mature stage and were classified as having high sensitivity at the seedling stage. Treating seedlings directly with ethylene showed that the response in tomatoes was still much greater than it was in lobelia, confirming that the lobelia seedlings are not very sensitive to ethylene (Fig. 6).

\section{Discussion}

Our research was conducted to determine whether the seedling hypocotyl elongation screen could be used to predict the ethylene sensitivity of market-ready bedding plants at horticultural maturity. The seedling hypocotyl elongation screen was previously used to identify zonal geranium cultivars with reduced sensitivity to ethylene, and these 

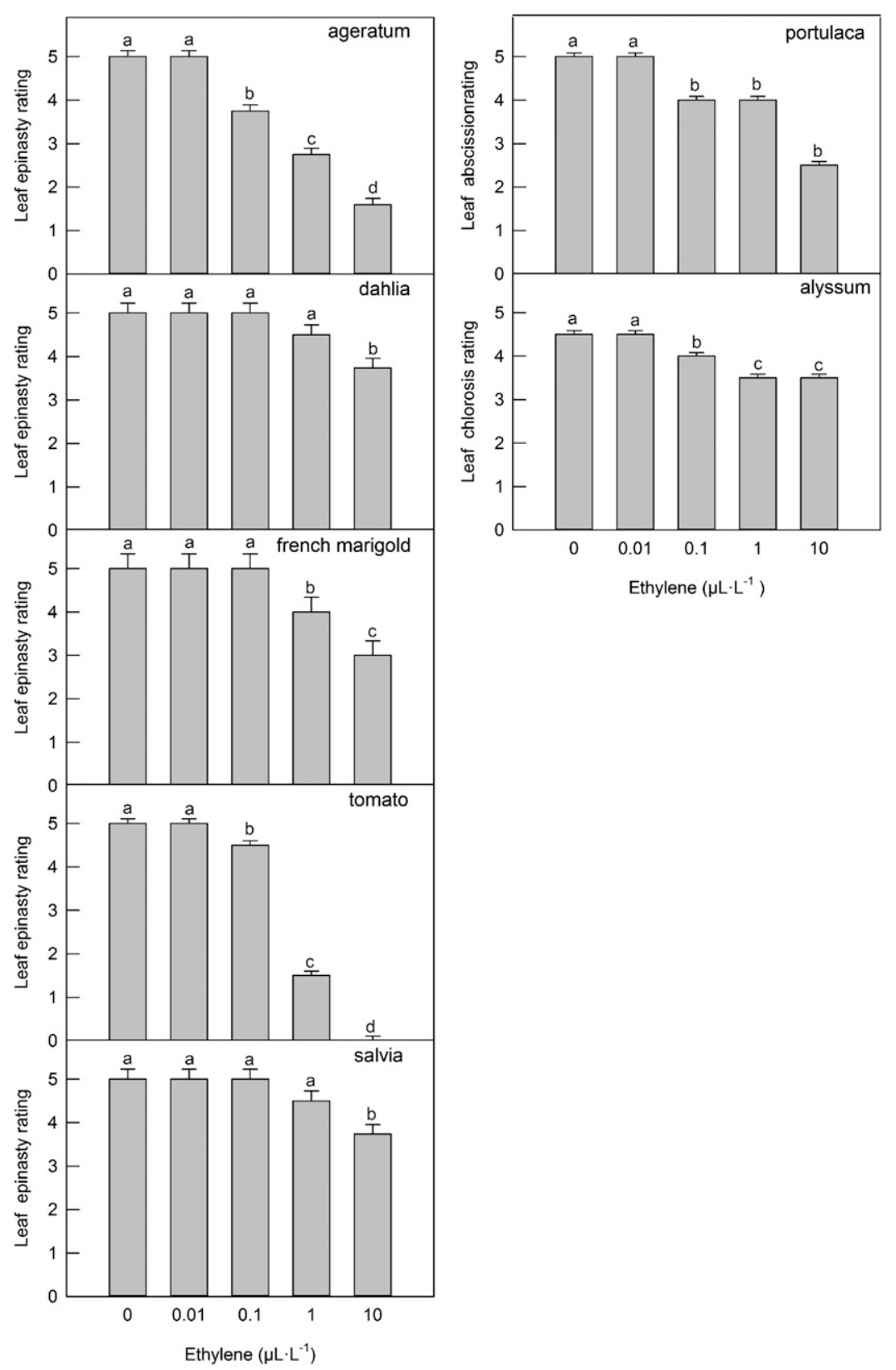

Fig. 4. Leaf quality of mature plants immediately after treatment $(0 \mathrm{~d})$ with ethylene. Species exhibiting leaf epinasty, leaf abscission, and leaf chlorosis after treatment with $0,0.01,0.1,1$, or $10 \mu \mathrm{L} \cdot \mathrm{L}^{-1}$ ethylene for $24 \mathrm{~h}$. Ratings were assigned based on the percentage of leaves on the plant showing each symptom: $5=$ $0 \%, 4=1 \%$ to $20 \%, 3=21 \%$ to $40 \%, 2=41 \%$ to $60 \%, 1=61 \%$ to $80 \%, 0=81 \%$ to $100 \%$. Bars represent the average visual rating, error bars represent the SE, and letters above the error bars show significance based on separation presented as the least squares means using $\alpha=0.05$ for significance.

differences in sensitivity were validated in mature plants using a petal abscission assay (Clark et al., 2001). We found that the seedling screen did not always predict mature plant ethylene sensitivity.

The most striking differences between the seedling and mature plant screens were observed in lobelia, salvia, viola, and pansy. The hypocotyl elongation screen indicated that lobelia and salvia seedlings had low sensitivity to ethylene, whereas mature plant screens indicated that they had high sensitivity due to high rates of flower senescence and abscission, respectively. The seedling screen makes the assumption that constitu- tive levels of ACC oxidase in the seedling will convert the applied ACC to ethylene and that the seedling hypocotyl will be responsive to that ethylene in a dose-dependent manner (Guzman and Ecker, 1990; Yang and Adams, 1979). It is possible that the lack of response that we observed in salvia and lobelia seedlings was the result of lower levels of ACC oxidase activity and reduced conversion of the applied ACC to ethylene. Treating lobelia seedlings directly with ethylene gas also resulted in only a small reduction in hypocotyl elongation, confirming that these seedlings have reduced sensitivity to ethylene (Fig. 6). Both viola and pansy showed the opposite response with seedlings exhibiting high sensitivity and mature plants receiving a low sensitivity rating resulting from the ethylene-induced senescence of only a few flowers. There is very little information available on ethylene responses in the genus viola. The Flower and Plant Care Guide (Nell and Reid, 2000) indicates that pansies are not sensitive to ethylene, whereas Rogers (1985) identifies pansy as one of the crops with intermediate susceptibility to damage from ethylene pollution. For these four species in particular, the seedling screen would not provide an adequate prediction of the ethylene sensitivity of mature, market-ready plants.

In six (ageratum, angelonia, nemesia, tomato, marigold, and zinnia) of the 18 species, the seedling screen and the mature plant screen resulted in identical classifications. Although it may be possible to consistently predict mature plant sensitivity using the seedling hypocotyl elongation screen in these species, additional cultivars should be evaluated to determine if the response is consistent between cultivars. Ethylene sensitivity differences have been described between cultivars and varieties within a species (Jones et al., 2001; Macnish et al., 2011; Serek and Reid, 2000; Serek and Sisler, 2001; Sisler et al., 1996; Woodson and Lawton, 1988). In carnations, which are generally considered to have high sensitivity to ethylene, breeding programs have selected for reduced ethylene sensitivity to create cut carnation varieties with extended vase life (Onozaki et al., 2001).

In an additional eight species (alyssum, dahlia, gomphrena, petunia, phlox, portulaca, snapdragon, and torenia), classifications differed by one category. In phlox, for example, seedlings were classified as high sensitivity and mature plants were classified as medium sensitivity. Although these classifications are only approximate, they are based on responses that were consistently observed among plant replicates and between independent experiments. These classifications may also vary slightly from those reported in the literature due to the specific cultivars that were selected for evaluation (Nell and Reid, 2000). In this evaluation, the seedling response was based on quantitative measurements of hypocotyl length, whereas mature plant classifications relied on a more subjective visual rating system to evaluate the severity of the response. Therefore, it may be possible to improve on the reliability of these classifications by using a more quantitative assessment of mature plant responses.

Contrasting effects of ethylene have been observed between plant species but also within different plant organs and at different developmental stages (Smalle and Van Der Straeten, 1997). The responsiveness of flower petals to ethylene is dependent on the physiological age of the tissue. In most species, flower buds are less sensitive to ethylene damage than open flowers, and ethylene sensitivity increases from flower bud to anthesis (i.e., flower opening) (Borochov and Woodson, 1989). In carnation flowers, 


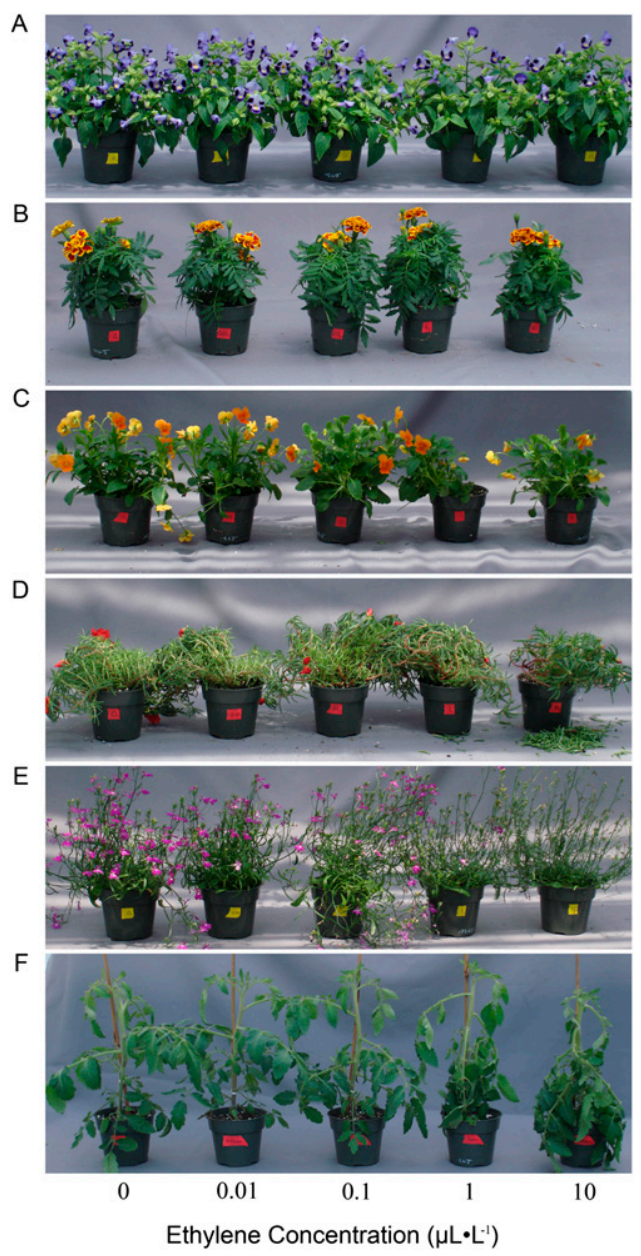

Fig. 5. Visual observations of mature plants after treatment with ethylene gas. Torenia (A), marigold (B), pansy $(\mathbf{C})$, portulaca $(\mathbf{D})$, lobelia $(\mathbf{E})$, and tomato $(\mathbf{F})$ are shown immediately after treatment $(0 \mathrm{~d})$ with $0,0.01,0.1,1$, or $10 \mu \mathrm{L} \cdot \mathrm{L}^{-1}$ for $24 \mathrm{~h}$ (seen from left to right).

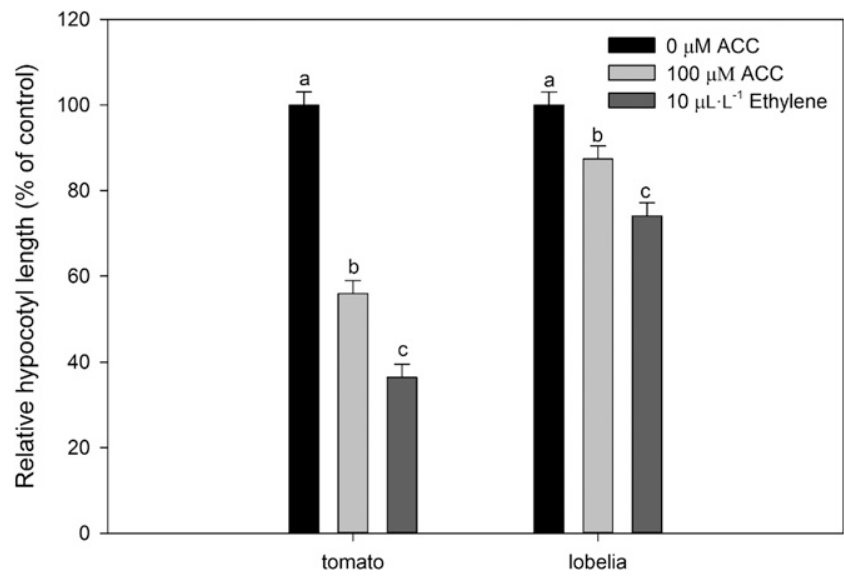

Fig. 6. Relative hypocotyl lengths of tomato and lobelia seedlings treated with 1-aminocyclopropane-1carboxylic acid (ACC) or ethylene gas. Seeds were sown on filter paper saturated with ACC at 0 or $100 \mu \mathrm{M}$ and exposed to 0 or $10 \mu \mathrm{L} \cdot \mathrm{L}^{-1}$ ethylene. Seedling hypocotyl length was measured at $7 \mathrm{~d}$ (tomato) and $14 \mathrm{~d}$ (lobelia) after germination. Bars represent the relative hypocotyl length as a percent of the control $\left(0 \mu \mathrm{M} \mathrm{ACC} / 0 \mu \mathrm{L} \cdot \mathrm{L}^{-1}\right.$ ethylene $)$. Error bars represent the SE, and letters above the error bars represent significance between treatments within a species based on separation presented as the least squares means using $\alpha=0.05$ for significance.

ethylene sensitivity then decreases from anthesis to senescence (Onozaki et al., 2004). In contrast, ethylene sensitivity increases from anthesis to senescence or abscission in petunia (Whitehead and Halevy, 1989), geranium (Evenson, 1991), portulaca (Ichimura and Suto, 1998), and torenia (Goto et al., 1999). The differences observed in our work between seedlings and mature plants can be explained by these developmental differences in ethylene responsiveness.

We used 10 concentrations of ACC in our seedling screens to determine which concentrations resulted in a reduction in hypocotyl elongation and to quantify the extent of that reduction compared with untreated control seedlings. We found that the percent hypocotyl reduction at $100 \mu \mathrm{M}$ as compared with controls (i.e., the relative hypocotyl length) identified the most significant differences and allowed us to classify the species into low, medium, and high sensitivity. Angelonia, dahlia, lobelia, salvia, and zinnia hypocotyl length (at $100 \mu \mathrm{M}$ ACC) was not significantly reduced compared with controls $(0 \mu \mathrm{M}$ ACC $)$. Relative hypocotyl length was consistently below $100 \%$, so these species were classified as having low ethylene sensitivity rather than classifying them as insensitive. It is possible that higher concentrations of ACC could be required to inhibit hypocotyl elongation in these species. For most species, using only 0 and $100 \mu \mathrm{M}$ ACC should be sufficient to quickly screen for seedling ethylene sensitivity. For the purposes of identifying plants that can be damaged by ethylene, and which would benefit from 1-MCP treatment, this simplified approach and the resulting three sensitivity classifications will be adequate. A more comprehensive dose-response analysis may be required to identify more subtle differences between cultivars.

The triple response screen used to identify ethylene response mutants involves germinating seedlings on MS media containing ACC (Clark et al., 2001; Guzman and Ecker, 1990). For our hypocotyl elongation screen, we germinated the seedlings on sterile filter paper that was saturated with ACC. In ageratum, lobelia, and snapdragon, the relative hypocotyl elongation in the presence of $100 \mu \mathrm{M}$ ACC was within $5 \%$ when sown on filter paper saturated with ACC or on MS media containing ACC (Supplemental Fig. 1). This approach saved time and resources because large volumes of MS media did not have to be prepared, and seeds did not require sterilization. Time-saving modifications, like these, make our seedling hypocotyl elongation screen a much more efficient highthroughput screen for ethylene sensitivity.

Many excellent experiments have been conducted to evaluate the ethylene sensitivity of foliage plants, flowering plants, and cut flowers (Dole et al., 2009; Macnish et al., 2011; Woltering, 1987; Woltering and Van Doorn, 1988). Woltering (1987) evaluated 52 ornamental pot plants using a protocol that involved treating mature plants with four concentrations of ethylene for two different exposure times. Flower abscission and senescence were observed after a 24-h ethylene treatment (at up to $15 \mu \mathrm{L} \cdot \mathrm{L}^{-1}$ ), whereas most vegetative symptoms were not observed until after $72 \mathrm{~h}$ of treatment. Flower abscission was the most common ethylene symptom, occurring in $65 \%$ of the species evaluated, and leaf senescence was the least common symptom occurring in less than $4 \%$ of the 
species (Woltering, 1987). In our study, we observed symptoms of leaf epinasty in five of the 18 species $(28 \%)$, whereas ethyleneinduced leaf chlorosis and abscission were observed only in alyssum and portulaca, respectively. We may have seen increased vegetative symptom severity if our $10-\mu \mathrm{L} \cdot \mathrm{L}^{-1}$ treatment went for $72 \mathrm{~h}$ or longer. We observed flower senescence $(50 \%$ of species) and flower abscission (44\% of species) at a similar frequency in the 18 bedding plants that were selected for evaluation.

Mature plant responses are often similar (in symptoms and extent) among plants within a family (Van Doorn, 2001, 2002). Whereas the seedling hypocotyl elongation screen cannot be used to predict unknown plant sensitivity without preliminary evaluations of mature plants, it may be possible to use this screen for a high-throughput analysis of species and cultivars within plant families where ethylene sensitivity at the seedling stage has been shown to correlate with mature plant sensitivity. The development of a simple and reliable screen for evaluating seedling and mature plant sensitivity will provide breeders, growers, transporters, and retailers with critical information about a plant's ethylene sensitivity. These screens can be used to evaluate new PIs and to identify cultivars that are less sensitive to ethylene and are better suited for long-distance transport. Growers and transporters can also use this information to determine which crops should be treated with ethylene inhibitors like 1-MCP to enhance their postproduction quality. Plants in both the medium and high classifications would benefit from postproduction treatment with 1-MCP to prevent symptoms of ethylene damage.

\section{Literature Cited}

Abeles, F.B., P.W. Morgan, and M.E. Saltveit, Jr. 1992. Ethylene in plant biology. $2^{\text {nd }}$ Ed. Academic Press, San Diego, CA.

Abramoff, M.D., P.J. Magalhaes, and S.J. Ram. 2004. Image Processing with ImageJ. Biophotonics Intl. 11:36-42.

Alexander, L. and D. Grierson. 2002. Ethylene biosynthesis and action in tomato: A model for climacteric fruit ripening. J. Expt. Bot. 53:20392055.

Alonso, J., T. Hirayama, G. Roman, S. Nourizadeh, and J. Ecker. 1999. Ein2 a bifunctional transducer of ethylene and stress response in Arabidopsis. Science 284:2148-2152.

Barry, C.S., E.A. Fox, H.C. Yen, S.H. Lee, T.J. Ying, D. Grierson, and J.J. Giovannoni. 2001. Analysis of the ethylene response in the epinastic mutant of tomato. Plant Physiol. 127:58-66.

Bleecker, A.B., M.A. Estelle, C. Somerville, and H. Kende. 1988. Insensitivity to ethylene conferred by a dominant mutation in Arabidopsis thaliana. Science 241:1086-1089.
Borochov, A. and W.R. Woodson. 1989. Physiology and biochemistry of flower petal senescence. Hort. Rev. 11:15-43.

Chang, C., S.F. Kwok, A.B. Bleecker, and E.M. Meyerowitz. 1993. Arabidopsis ethyleneresponse gene ETR1: Similarity of product to two component regulators. Science 262:539544.

Clark, D.G., C. Dervinis, J. Barrett, and T.A. Nell. 2001. Using a seedling hypocotyl elongation assay as a genetic screen for ethylene sensitivity of seedling geranium cultivars. HortTechnology 11:297-302.

Dole, J.M., V. Zenaida, F.L. Fanelli, and W. Fonteno. 2009. Postharvest evaluation of cut dahlia, linaria, lupine, poppy, rudbeckia, trachelium, and zinnia. HortTechnology 19:593-600.

Ecker, J.R. 1995. The ethylene signal transduction pathway in plants. Science 268:667-675.

Evenson, K.B. 1991. Ethylene responsiveness changes in Pelargonium $\times$ domesticum florets. Physiol. Plant. 82:400-412.

Goeschl, J.D. and S.J. Kays. 1975. Concentration dependencies of some effects of ethylene on etiolated pea, peanut, bean, and cotton seedlings. Plant Physiol. 55:670-677.

Goto, R., R. Aida, M. Shibata, and K. Ichimura 1999. Role of ethylene on flower senescence of Torenia. J. Jpn. Soc. Hort. Sci. 68:263-268.

Guzman, P. and J.R. Ecker. 1990. Exploiting the triple response of Arabidopsis to identify ethylene-related mutants. Plant Cell 2:513-523.

Ichimura, K. and K. Suto. 1998. Role of ethylene in acceleration of flower senescence by filament wounding in Portulaca hybrid. Plant Physiol. 104:603-607.

Jones, M.L. and N. Edelman. 2013. How to prevent ethylene-related losses during the postproduction care and handling of crops. Greenhouse Mgt. 32:38-44.

Jones, M.L., E.S. Kim, and S.E. Newman. 2001. Role of ethylene and 1-MCP in flower development and petal abscission in zonal geraniums. HortScience 36:1305-1309.

Jones, M.L. and P. Ling. 2012. Preventing ethylene damage in the production greenhouse. Greenhouse Mgt. 31:45-47.

Knight, L.I., R.C. Rose, and W. Crocker. 1910. Effects of various gases and vapors upon etiolated seedlings of the sweet pea. Science 311:635-636.

Lanahan, M.B., H.C. Yen, J.J. Giovannoni, and H.J. Klee. 1994. The never ripe mutation blocks ethylene perception in tomato. Plant Cell 6:521-530.

Macnish, A.J., R.T. Leonard, and T.A. Nell. 2011. Sensitivity of potted foliage plant genotypes to ethylene and 1-methylcyclopropene. HortScience 46:1127-1131.

Nell, T.A. and M.S. Reid. 2000. Flower and plant care: The 21 st century approach. Society of American Floriculture, Alexandria, VA.

Onozaki, T., H. Ikeda, and M. Shibata. 2004. Video evaluation of ethylene sensitivity after anthesis in carnation (Dianthus caryophyllus L.) flowers. Sci. Hort. 99:187-197.

Onozaki, T., H. Ikeda, and T. Yamaguchi. 2001. Genetic improvement of vase life of carnation flowers by crossing and selection. Sci. Hort. 87:107-120.

Rogers, M.N. 1985. Air pollution, p. 274-314. In: Mastalerz, J.W. and E.J. Holcomb (eds.). Bedding plants III. 3rd Ed. Pennsylvania Flower Growers, PA.

Serek, M. and M.S. Reid. 2000. Ethylene and postharvest performance of potted kalanchoe. Postharvest Biol. Technol. 18:43-48.

Serek, M. and E.C. Sisler. 2001. Efficacy of inhibitors of ethylene binding in improvement of the postharvest characteristics of potted flowering plants. Postharvest Biol. Technol. 23:161166.

Serek, M., E.C. Sisler, and M.S. Reid. 1995. Effects of 1-MCP on the vase life and ethylene response of cut flowers. Plant Growth Regulat. 16:93-97.

Sisler, E.C., E. Dupille, and M. Serek. 1996. Effect of 1-methylcyclopropene and methylenecyclopropene on ethylene binding and ethylene action on cut carnations. Plant Growth Regulat. 18:79-86.

Smalle, J., M. Haegman, J. Kurepa, M. Van Montagu, and D. Van Der Straeten. 1997. Ethylene can stimulate Arabidopsis hypocotyl elongation in the light. Proc. Natl. Acad. Sci. USA 94:2756-2761.

Smalle, J. and D. Van Der Straeten. 1997. Ethylene and vegetative development. Physiol. Plant. 100:593-605.

Van Doorn, W.G. 2001. Categories of petal senescence and abscission: A re-evaluation. Ann. Bot. (Lond.) 87:447-456.

Van Doorn, W.G. 2002. Effect of ethylene on flower abscission: A survey. Ann. Bot. (Lond.) 89:689-693.

Watada, A.E., R.C. Herner, A.A. Kader, R.J. Romani, and G.L. Staby. 1984. Terminology for the description of developmental stages of horticultural crops. HortScience 19:20-21.

Whitehead, C.S. and A.H. Halevy. 1989. Ethylene sensitivity: The role of short-chain saturated fatty acids in pollination-induced senescence of Petunia hybrida flowers. Plant Growth Regulat. 8:41-54.

Woltering, E.J. 1987. Effects of ethylene on ornamental pot plants: A classification. Sci. Hort. 31:283-294.

Woltering, E.J. and W.G. Van Doorn. 1988. Role of ethylene in senescence of petals- morphological and taxonomical relationships. J. Expt. Bot. 39:1605-1616.

Woodson, W.R. and K.A. Lawton. 1988. Ethyleneinduced gene expression in carnation petals. Relationship to autocatalytic ethylene production and senescence. Plant Physiol. 87:498503.

Yang, S.F. and D.O. Adams. 1979. Ethylene biosynthesis: Identification of 1-aminocyclopropane1-carboxylic acid as an intermediate in the conversion of methionine to ethylene. Proc. Natl. Acad. Sci. USA 76:170-174.

Zhong, S., H. Shi, C. Xue, L. Wang, Y. Xi, J. Li, P.H. Quail, X.W. Deng, and H. Guo. 2012. A molecular framework of light-controlled phytohormone action in Arabidopsis. Curr. Biol. 22:1530-1535. 


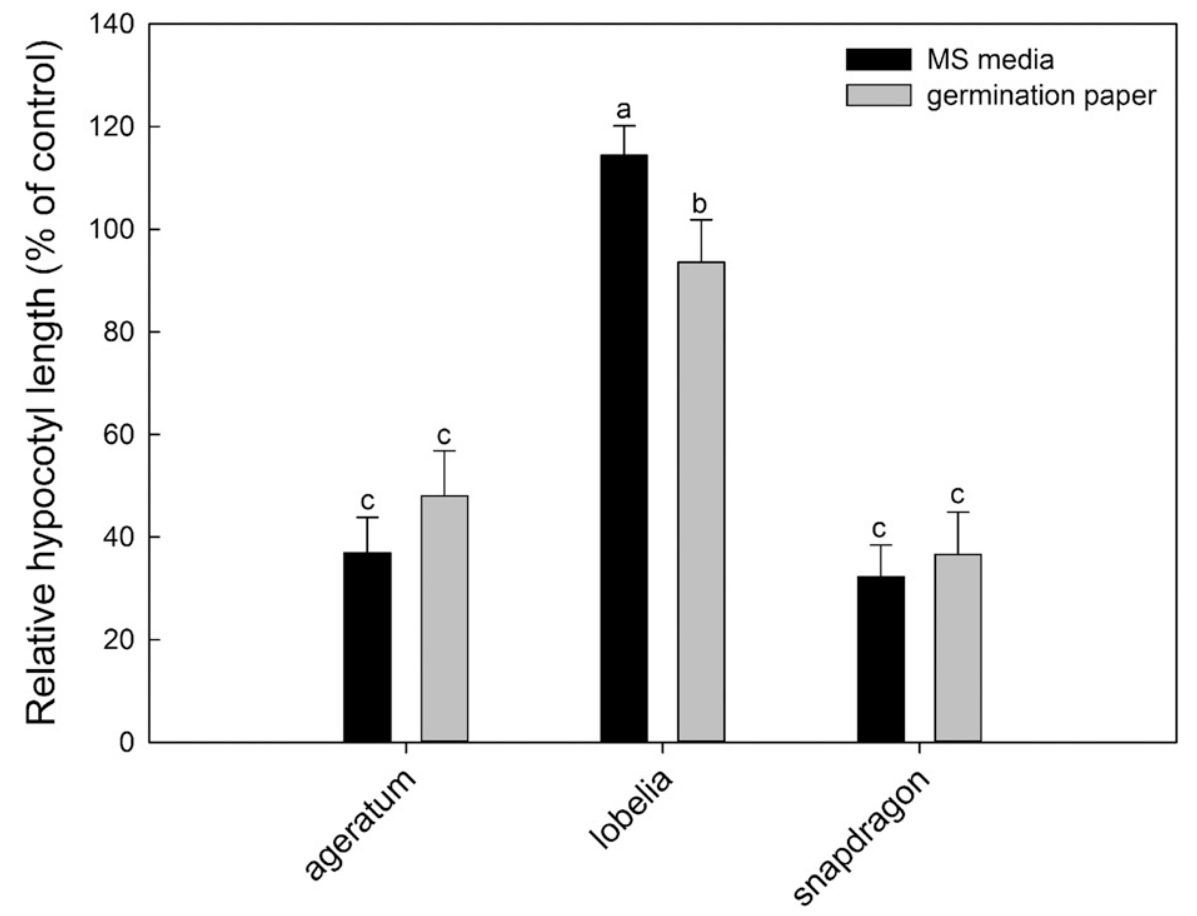

Supplemental Figure. 1. Relative hypocotyl lengths of seedlings germinated on Murashige and Skoog (MS) media or sterile filter paper containing $100 \mu \mathrm{M}$ 1-aminocyclopropane-1-carboxylic acid (ACC). Bars represent the hypocotyl length at $100 \mu \mathrm{M}$ ACC as a percentage of the controls $(0 \mu \mathrm{M}$ ACC). Error bars represent the SE and letters above the error bars represent significance between species based on the separation presented as the least squares means using $\alpha=$ 0.05 for significance. Black bars represent hypocotyl lengths of seedlings germinated on MS media and grey bars represent hypocotyl lengths of seedlings germinated on filter paper. 
A
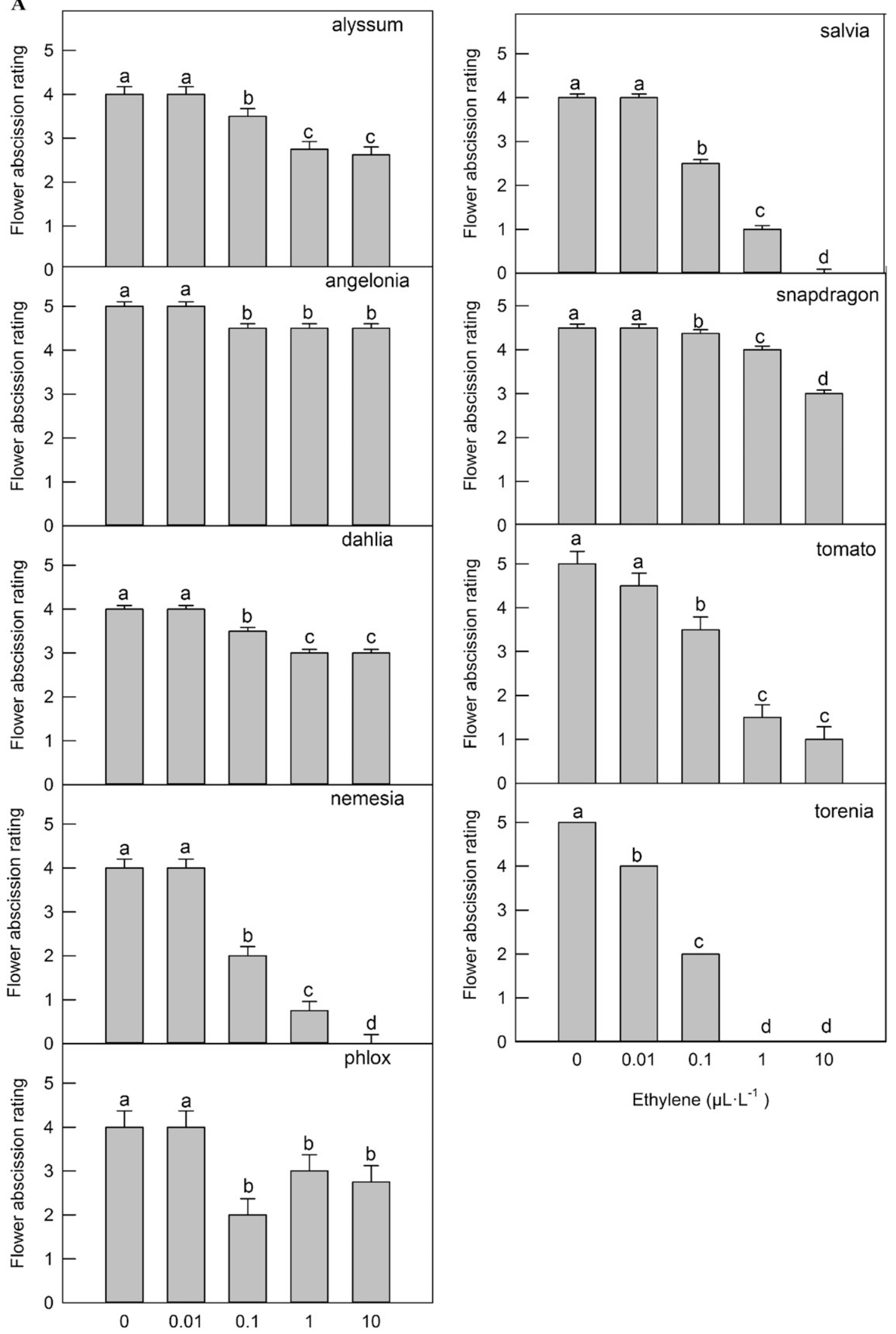

Ethylene $\left(\mu \mathrm{L} \cdot \mathrm{L}^{-1}\right)$

Ethylene $\left(\mu \mathrm{L} \cdot \mathrm{L}^{-1}\right)$

Supplemental Figure. 2. Flower quality of mature plants $1 \mathrm{~d}$ after treatment with ethylene. Species exhibiting flower abscission $(\mathbf{A})$ and flower senescence (B) after treatment with $0,0.01,0.1,1$, or $10 \mu \mathrm{L} \cdot \mathrm{L}^{-1}$ ethylene for $24 \mathrm{~h}$. Ratings were assigned based on the percentage of flowers on the plant showing symptoms: $5=$ $0 \%, 4=1 \%$ to $20 \%, 3=21 \%$ to $40 \%, 2=41 \%$ to $60 \%, 1=61 \%$ to $80 \%, 0=81 \%$ to $100 \%$. Bars represent the average visual rating, error bars represent the sE, and letters above the error bars show significance based on separation presented as the least squares means using $\alpha=0.05$ for significance. 

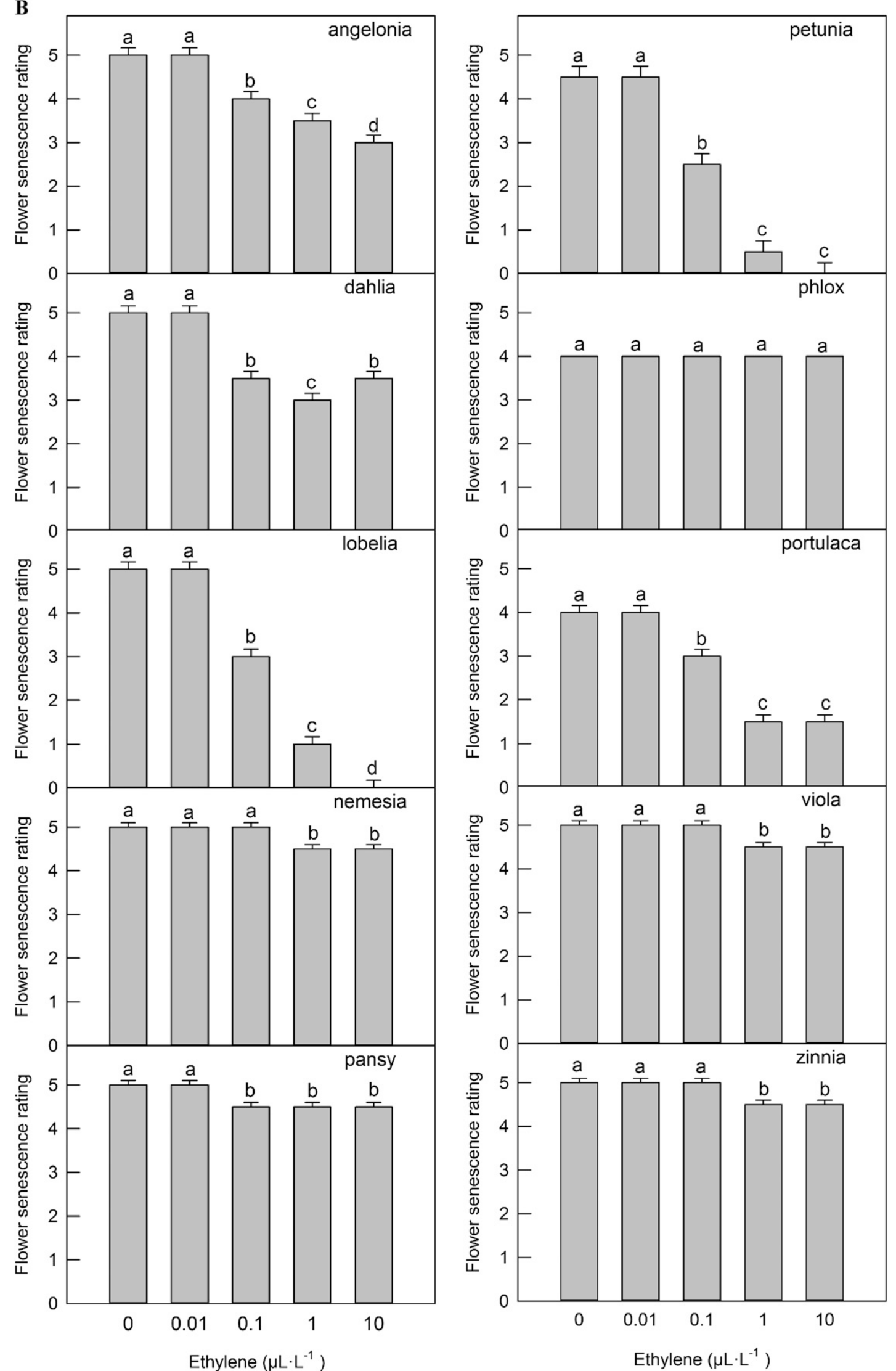

Supplemental Figure. 2. Continued. 

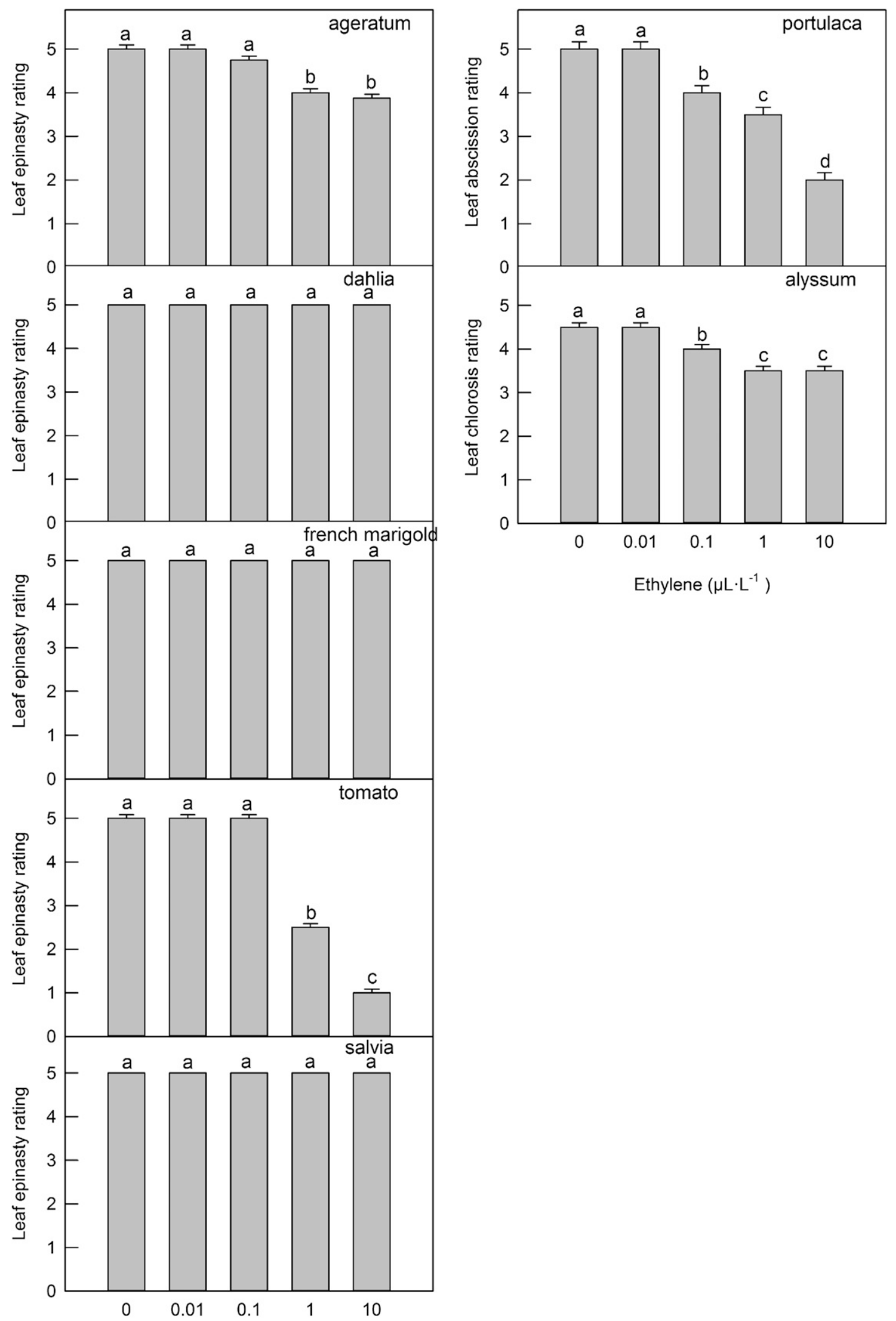

e $\left(\mu \mathrm{L} \cdot \mathrm{L}^{-1}\right)$

Ethylene $\left(\mu \mathrm{L} \cdot \mathrm{L}^{-1}\right)$

Supplemental Figure. 3. Leaf quality of mature plants $1 \mathrm{~d}$ after treatment with ethylene. Species exhibiting leaf epinasty, leaf abscission, and leaf chlorosis after treatment with $0,0.01,0.1,1$, or $10 \mu \mathrm{L} \cdot \mathrm{L}^{-1}$ ethylene for $24 \mathrm{~h}$. Ratings were assigned based on the percentage of leaves on the plant showing each symptom: $5=$ $0 \%, 4=1 \%$ to $20 \%, 3=21 \%$ to $40 \%, 2=41 \%$ to $60 \%, 1=61 \%$ to $80 \%, 0=81 \%$ to $100 \%$. Bars represent the average visual rating, error bars represent the sE, and letters above the error bars show significance based separation presented as the least squares means using $\alpha=0.05$ for significance. 
$\mathbf{A}$
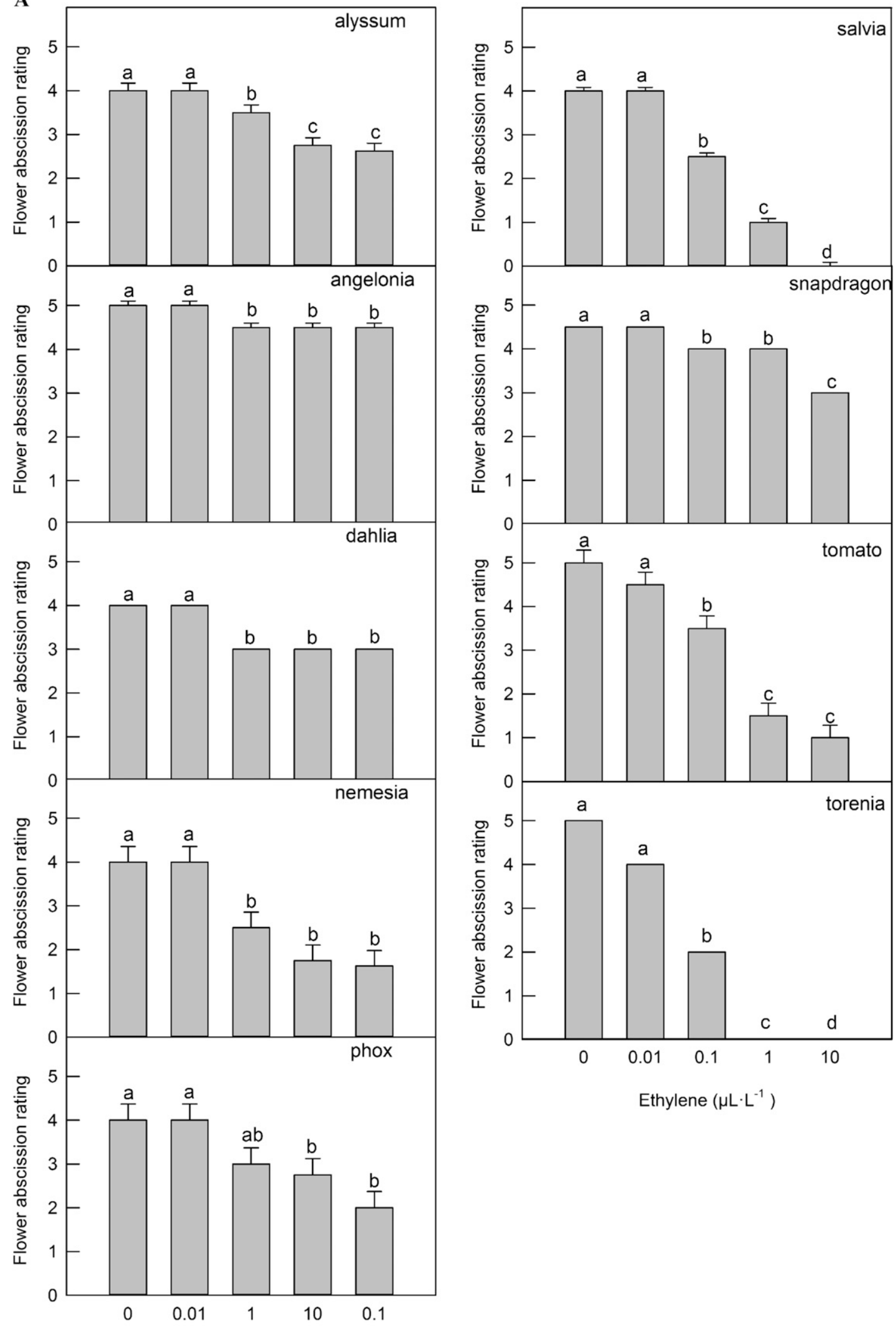

Ethylene $\left(\mu L \cdot L^{-1}\right)$

Ethylene $\left(\mu \mathrm{L} \cdot \mathrm{L}^{-1}\right)$

Supplemental Figure. 4. Flower quality of mature plants $2 \mathrm{~d}$ after treatment with ethylene. Species exhibiting flower abscission (A) and flower senescence (B) after treatment with $0,0.01,0.1,1$, or $10 \mu \mathrm{L} \cdot \mathrm{L}^{-1}$ ethylene for $24 \mathrm{~h}$. Ratings were assigned based on the percentage of flowers on the plant showing symptoms: $5=$ $0 \%, 4=1 \%$ to $20 \%, 3=21 \%$ to $40 \%, 2=41 \%$ to $60 \%, 1=61 \%$ to $80 \%, 0=81 \%$ to $100 \%$. Bars represent the average visual rating, error bars represent the sE, and letters above the error bars show significance based on separation presented as the least squares means using $\alpha=0.05$ for significance. 

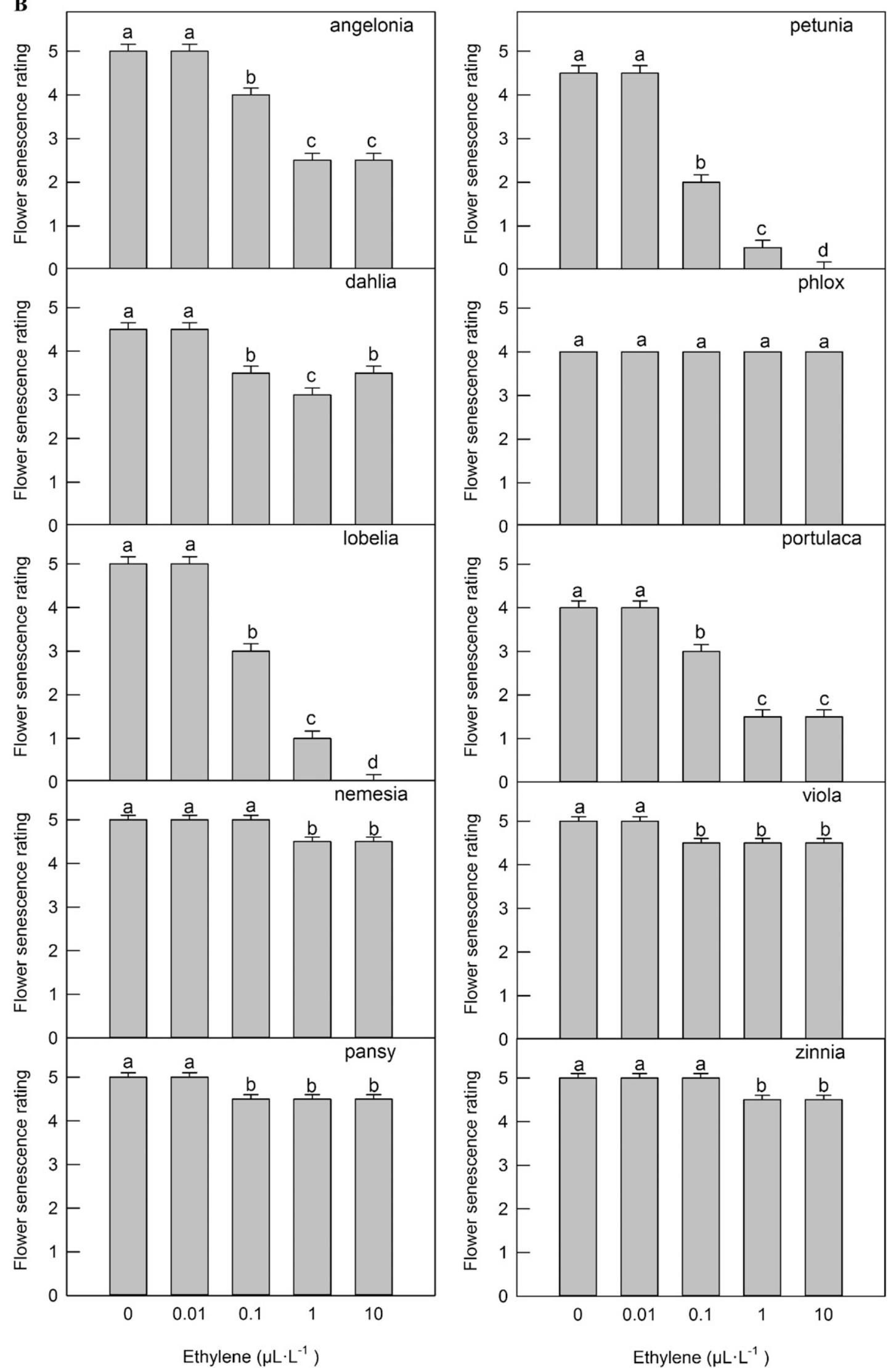

Supplemental Figure. 4. Continued. 


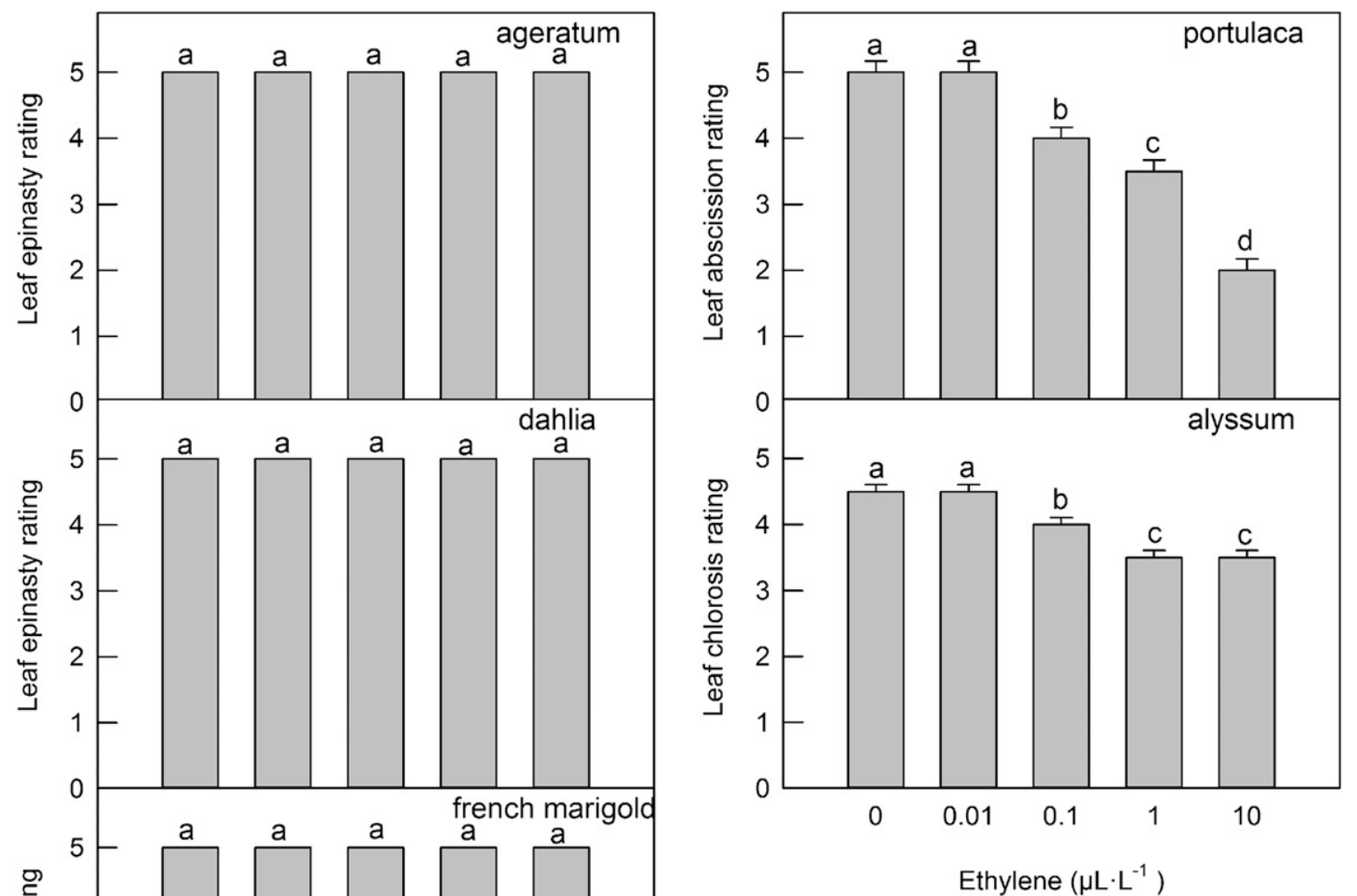

Ethylene $\left(\mu \mathrm{L} \cdot \mathrm{L}^{-1}\right)$ 